\title{
Periódicos científicos da Educação Física: Proposta de Avaliação
}

Amarílio Ferreira Neto $^{1}$ e Ana Claudia Silverio Nascimento ${ }^{2}$

\section{Resumo}

Considerando a pouca adequação dos periódicos científicos da Educação Física brasileira aos padrões formais adotados nacional e internacionalmente para publicações, este artigo propõe um modelo para avaliação formal das revistas científicas da área. O objetivo do estudo é contribuir para a melhoria da qualidade das publicações da Educação Física, buscando proporcionar maior visibilidade para a produção científica. Baseia-se no formulário de avaliação de Krzyzanowski \& Ferreira (1998) em seu estudo Avaliação de periódicos científicos e técnicos brasileiros, com algumas modificações no modelo original.

Descritores: Educação Física, Periódicos científicos, Avaliação de periódicos científicos

\begin{abstract}
Considering the few appropriation ofthe scientiftc periodcs of the brazilian physical education a formal models adopteds nationaland internationalfor fublications, this article propose a model to formal valuations ofthe scientiftc magazines to the área. The study objective is contribute for the better to the quality ofPhysical Education publications, searching proportionate more visibility for the scientiftc production. Its based on valuation form created for Krzyzanowski \& Ferreira (1998) in its study Valuation of scientific periodes and brazilian technicals, with some modiftcations in original model.
\end{abstract}

Key words: Physical Education, Scientific periodcs, Valuation of scientific periodcs

\section{Introdução}

A comunicação situa-se no próprio coração da ciência. E para ela tão vital quanto a própria pesquisa, pois a esta não cabe reivindicar com legitimidade este nome enquanto não houver sido analisada e aceita pelos pares (Meadows, vii, 1999).

E com essa frase que Meadows abre o prefácio de seu livrou comunicação científica e é também ela que nos dá a exata noção do papel da comunicação científica no desenvolvimento da Ciência.

A partir da afirmação do autor, somos levados a pensar que a circulação dos conhecimentos gerados pela Ciência é inerente à própria concepção de Ciência. Assim, baseados na assertiva transcrita, podemos concluir que pensar a relevância da Ciência demanda, necessariamente, reconhecer a importância da informação científica, do conhecimento científico e, conseqüentemente, da comunicação científica (Targino, 2000).

A comunicação científica, como atividade ligada à produção, disseminação e uso da informação, pode ocorrer de dois modos distintos: o informal, que inclui trocas de cartas, contatos pessoais, comunicações orais, etc; e o formal, que inclui os artigos publicados em periódicos, capítulos de livros e os livros (Puerari, citado por Fávero, 1998, p. 39).

Entre os diversos canais de comunicação da Ciência, as publicações constituem importantes pólos de divulgação, principalmente devido à propriedade de permanência dos registros e seu alcance geográfico. Por isso, o debate sobre a sua importância é corrente na comunidade científica, sobretudo, pelo papel assumido pelos periódicos científicos - um dos meios mais usados para difusão do conhecimento - no processo de avali- 
ação da produção científica no País.

As publicações constituem fóruns privilegiados para anunciar resultados, submeter a produção a julgamento e receber contribuições. Ou seja, elas possibilitam a continuidade do processo evolutivo do conhecimento.

Sem desejar enumerar, neste momento, vantagens e desvantagens das publicações científicas, devemos reconhecer que os periódicos representam hoje um dos principais canais para veiculação dos novos saberes produzidos e circulantes no interior da comunidade científica, além de propiciar o reconhecimento científico, uma vez que atuam como meio de estabelecimento da propriedade científica.

Dessa forma, no contexto acadêmico, os periódicos científicos perpassam o papel de disseminador da pesquisa. Eles estão intimamente relacionados com o sistema de recompensa acadêmica e com o reconhecimento pelos pares.

Paradoxalmente, ao mesmo tempo em que são reconhecidos e valorizados como importantes pólos de divulgação da produção científica, ${ }^{1}$ os periódicos científicos enfrentam sérias dificuldades para sua manutenção. Essas dificuldades dizem respeito aos seus aspectos de qualidade, normalização, distribuição, falta de continuidade das edições e ausência de recursos humanos capacitados na área, o que acarreta um certo amadorismo em sua produção.

Todos esses problemas acabam por dificultar a inserção desses periódicos em bases de dados nacionais e internacionais, tendo como conseqüência a pouca visibilidade da produção científica publicada.

Nesse sentido, por entendermos que um certo amadorismo ainda se faz presente no cenário brasileiro de publicação de revistas científicas ${ }^{2}$ da Educação Física, que ainda carecem de padrões mínimos de qualidade editorial e gráfica, pretendemos neste artigo propor um instrumento para a avaliação formal dessas revistas, objetivando apontar os critérios de qualidade exigidos para uma publicação científica.
Assim, o artigo disserta, de início, sobre aspectos diversos relacionados com os periódicos científicos, como sua conceituação, evolução, funções, dificuldades e papel na construção da Ciência. Posteriormente, segue uma abordagem sobre a metodologia de avaliação de periódicos científicos e técnicos buscando apresentar os critérios observados, bem como o instrumento proposto para avaliar os periódicos que divulgam a produção da Educação Física brasileira.

\section{Periódicos Científicos: Conceito e Evolução}

A complexidade do estudo dos periódicos brasileiros começa pela própria definição do que sejam essas publicações. Stumpf (1999) chama a atenção para o fato de, na literatura brasileira, palavras como publicações periódicas, periódicos, publicações seriadas e revistas se apresentarem tanto como sinônimos, como gênero e espécie. Em seu entendimento, as publicações seriadas são consideradas como a categoria maior e mais abrangente que inclui, como espécie, periódicos, jornais, anais de sociedades científicas, entre outras.

Buscando apresentar uma definição para os periódicos, a autora afirma que eles

...se constituem em uma das categorias das publicações seriadas, que apresentam como características particulares serem feitas em partes ou fasciculos, numeradas progressiva ou cronologicamente, reunidas sob um titulo comum, editadas em intervalos regulares, com a intenção de continuidade infinita, formadas por contribuições, na forma de artigos assinados, sob a direção de um editor, com um plano definido que indica a necessidade de um planejamento prévio (Stumpf, 1999, p. 1).

$A$ polêmica em torno dos periódicos não se restringe à sua nomenclatura. Existe falta de consenso ainda entre os estudiosos acerca da classificação do que é ou não científico.

Para dirimir as dúvidas, como alerta Targino (2000), é preciso estabelecer parâmetros mínimos. Assim, a autora informa que Braga \& Oberhofer, em 1982, com base na natureza do material veiculado, estabelece- 


\section{임}

ram a seguinte definição para os periódicos brasileiros:

São científicos quando mais de $50 \%$ de seu conteúdo são artigos assinados resultantes de investigações científicas; técnicos quando dedicam acima de 50\% a artigos assinados emitindo comentários, opiniões, pontos de vista sobre determinados temas; e de divulgação quando priorizam notícias curtas, informes e similares (Braga \& Oberhofer, citados por Targino, 2000, p. 110).

Desde o seu surgimento, no século XVII, os periódicos científicos passaram a desempenhar importante papel no processo de comunicação da Ciência. Eles surgiram como uma evolução do sistema particular de comunicação que era realizado por meio da troca de cartas entre os investigadores e das atas ou memórias das reuniões científicas.

As cartas foram o primeiro meio utilizado pelos cientistas para a transmissão de suas idéias. Entretanto, por serem muito pessoais e lentas para divulgação das novas descobertas e limitadas a um pequeno número de pessoas, elas não se constituíram no método ideal para a comunicação científica. Já as atas compreendiam as transcrições das descobertas relatadas em reuniões que eram impressas na forma resumida e distribuídas aos membros para servirem de consulta.

O surgimento do periódico, entretanto, não significou o fim desses dois tipos de registros mencionados. Ele provocou uma (re)definição de papel entre os diversos canais de divulgação da Ciência: as cartas passaram a ter um caráter de comunicação pessoal entre os cientistas e as atas passaram a se constituir em um documento de registro dos trabalhos apresentados em reuniões científicas e profissionais.

As duas primeiras revistas científicas surgiram em 1665 com dois meses de diferença entre suas primeiras publicações. Journal des Sçavans e Philosophical Transactions serviram de modelo para outros periódicos publicados por sociedades e academias européias.

Em função do aumento do número de pesquisadores e, conseqüentemente, de pesquisas e dos avanços técnicos de impressão e fabricação, houve um crescimen- to na quantidade de revistas científicas em circulação durante o século XIX.

Esse crescimento manteve-se no século $\mathrm{XX}$, pois as revistas também passaram a ser publicadas por editores comerciais, pelo Estado e por universidades.

Durante as décadas de 1970 e 1980, algumas mudanças puderam ser observadas, tanto no processo de produção das revistas quanto de acesso. $\mathrm{O}$ avanço da editoração eletrônica imprimiu maior rapidez no seu processo de produção, surgindo ainda a possibilidade de se obter on-line o texto indexado pelas bases de dados.

O aparecimento dos periódicos eletrônicos, com o uso das redes de telecomunicações para transmissão eletrônica, foi a grande mudança que ocorreu na década de 1990. Esse fato desencadeou debates acerca das vantagens e desvantagens desse tipo de publicação. Autores como Stumpf(1996),Sabbatini (1999), Mueller (1999) e Ohira et al. (2000) indicam pontos positivos e negativos dos periódicos eletrônicos.

Entre os argumentos levantados em favor desse tipo de publicação, os autores apontam como a grande vantagem a rapidez nas etapas de elaboração (recebimento e registro dos artigos, pré-avaliação pelo editor ou comissão editorial, avaliação pelos consultores, reformulação e formatação segundo os padrões da revista) e o baixo custo das fases de impressão e distribuição.

Como desvantagem, Mueller (1999) alerta para a dificuldade que pode ser encontrada no reconhecimento de autoridade e propriedade, bem como de preservação do conhecimento.

As vantagens apresentadas pelos periódicos eletrônicos fizeram com que alguns pesquisadores acreditassem no declínio do periódico impresso. Entretanto, mesmo diante do grande aumento tanto do uso quanto do número de periódicos disponíveis na rede, Targino (2000) é enfática ao afirmar que vai ocorrer, ainda por algum tempo, uma coexistência pacífica entre os dois tipos de periódicos, com a prevalência de réplicas eletrônicas de versões impressas. 


\section{Papel do Periódico na construção da Ciência e Principais Problemas Enfrentados}

$\mathrm{Na}$ atualidade, entre os vários tipos de publicações, o periódico impresso é um dos canais mais usados pela comunidade científica, pois, por meio dele, o pesquisador expõe idéias, garante a propriedade científica e se submete à avaliação dos pares.

Para que cumpram essas funções, é necessário que os periódicos se estabeleçam e se consolidem. Entretanto, isso depende de uma estrutura que envolve a presença de uma comunidade científica engajada na atividade de pesquisa; da afluência de artigos para publicação; da existência de grupos que desempenhem funções de edição, avaliação, publicação, disseminação e recuperação; da existência de mercado representado por uma comunidade de usuários que o legitimem; de infra-estrutura para distribuição, recuperação e acesso às informações (Miranda, 1996).

Como nem sempre apresentam a estrutura acima citada, os periódicos publicados em países que não estão na fronteira do desenvolvimento, como é o caso do Brasil, não conseguem entrar no círculo dos mais prestigiados.

Muitos são os problemas enfrentados por essas revistas. Entre eles Mueller (1999), Stumpf (2000) e Ohira et al. (2000) indicam como os principais: a proliferação de periódicos como resultado da necessidade de publicar que atinge muitos cientistas, a dispersão de artigos, a formação deficiente do corpo editorial, o esquema de distribuição deficiente e a falta de padronização.

Como conseqüência desses fatores negativos, ocorre a pouca aceitabilidade das revistas científicas brasileiras no meio técnico e científico internacional. Por isso, é crescente a preocupação daqueles que estão envolvidos com o processo de editoração de revistas e com a melhoria da qualidade de suas publicações.

Para que possa ser considerado de boa qualidade, um periódico precisa publicar bons artigos, manter sua periodicidade e ser facilmente encontrado. Entretanto, essas características são dependentes umas das outras, formando um círculo vicioso difícil de romper e que pode ser expresso da seguinte forma:

...a a afluência de bons artigos [...] é conseqüência da regularidade da publicação e facilidade de acesso por leitores interessados. Qualidade de artigos, regularidade na publicação e facilidade de acesso permitem ao periódico ser incluido em base de dados internacionais e aumentar sua visibilidade. A visibilidade aumenta as chances de citação. O financiamento é mais acessivel aos periódicos que publicam bons artigos, são indexados e citados, ou seja, que têm boa reputação. A boa reputação se mantém com o rigor da seleção dos artigos. O rigor da seleção só pode ser aplicado onde há boa afluência de artigos. Mas a boa afluência de artigos depende de todo o resto... (Mueller, 1999, p- 4).

Assim, acompanhando uma tendência mundial, cientistas e estudiosos brasileiros dão prioridade aos periódicos de maior prestígio para a publicação de seus trabalhos.

Isso ocorre pois não há, no cenário brasileiro de publicações periódicas, uma imagem homogênea. A grande maioria dos títulos apresenta-se de forma irregular, alterando suas edições com períodos longos de ausência. Contudo, encontramos periódicos nos dois extremos: aqueles que se mantêm regularmente há décadas e aqueles que sofreram a síndrome dos três fascículos: o primeiro é publicado com euforia, o segundo com atraso e o terceiro e último, anos depois (Stumpf, 1999).

\section{Avaliação de Periódicos Científicos}

Devido à grande expansão experimentada pelas publicações científicas ao longo do século XX, a partir da década de 1960, como apontam Krzyzanowski \& Ferreira (1998), começam a surgir estudos com o objetivo de propor metodologias para avaliação das revistas científicas e técnicas. Esse fato já demonstrava a necessidade de definir parâmetros mensuráveis que pudessem refletir a qualidade da informação registrada. 
A avaliação dos periódicos, então, tornou-se um instrumento utilizado tanto pelas agências de fomento para definição de apoio às revistas, como pelos principais índices internacionais para a inclusão de títulos em seu banco de dados.

Entre as tentativas mais recentes de avaliação de periódicos, podemos citar: Castro et ai. (1996); Castro et ai. (1996) e Krzyzanowski \& Ferreira (1998).

Apoiando-se nas metodologias propostas por essas autoras, alguns grupos envolvidos com a publicação de periódicos brasileiros têm se mobilizado com o intuito de avaliar suas revistas, ${ }^{3}$ sobretudo impulsionados pela avaliação dos programas de pós-graduação no Brasil empreendida pela Coordenação de Aperfeiçoamento de Pessoal de Nível Superior (CAPES).

Nesse processo de avaliação dos cursos de pós-graduação, quatro fatores são tomados como indicadores de produção: artigo em periódicos; trabalhos apresentados em congressos; livros (capítulos, texto integral ou organização); e dissertações e teses. Desse conjunto, como afirmam Yamamoto et ai. $(1999$, p. 7) "...certamente há um incentivo à produção científica expressa em artigos em periódicos, a modalidade mais arbitrada dentre todas".

Portanto, o que notamos é uma preocupação crescente com a melhoria da qualidade dos periódicos brasileiros, objetivando maior visibilidade para a produção científica nacional.

Os estudos sobre avaliação de periódicos científicos têm reforçado a idéia de que as características formais desses veículos de comunicação são indicativas da sua qualidade e de que elas podem interferir no padrão de qualidade do seu conteúdo e na sua aceitação no processo de seleção de títulos a serem incluídos em bases de dados, principalmente se apresentarem características aclamadas internacionalmente.

O trabalho que ora desenvolvemos também se interessa pela realização da avaliação dos periódicos, levando em consideração que essa é uma preocupação atual dos profissionais que se interessam pela qualidade da informação científica, sejam eles autores, editores, publicadores, gerenciadores de sistemas de indexação e, principalmente, pesquisadores.

Isso se deve ao fato de diversas críticas estarem sendo realizadas quanto à publicação de revistas com baixa qualidade que não cumprem os critérios estabelecidos pela comunidade científica e com as quais vêm-se perdendo recursos, material publicado e o prestígio de al-

gumas instituições (Krzyzanowski \& Os estudos sobre avaliação Ferreira, 1998). de periódicos científicos têm Portanto, a pro- reforçado a idéia de que as posta de avaliação características formais que ora apresenta-desses veículos de mos toma-se com-comunicação são indicativas patível com a rea-da sua qualidade e de que lidade e o momen-elas podem interferir no to de publicação padrão de qualidade do seu científica no Brasil, conteúdo e na sua aceitação em que a discus-no processo de seleção de são sobre as carac-títulos a serem incluídos em terísticas dos peri-bases de dados, ódicos nas diver-principalmente se sas ciências tem apresentarem características estado em foco.

A realização deste internacionalmente. estudo foi impulsionada ainda pelo fato de acreditarmos que, em um

futuro muito próximo, a normalização das revistas científicas será um pré-requisito para avaliação. Ou seja, somente serão avaliadas as revistas que cumprirem as normas de publicação.

Como essa é a parte mais fácil de ser modificada em um periódico, entendemos que a disseminação do modelo aqui proposto pode contribuir para a melhoria da qualidade das revistas aparecendo como uma possibilidade de caminhar no sentido de que os periódicos produzidos com maior rigor resultem na oferta de artigos mais bem elaborados.

Imbuídos desse objetivo, realizamos um trabalho de avaliação dos principais periódicos da Educação Física 
brasileira, buscando conhecer os aspectos que ainda necessitam ser modificados para que esses possam ser incluídos nas bases de dados, garantindo maior visibilidade para a produção nacional da área. ${ }^{4}$

\section{Metodologia}

A avaliação de periódicos científicos pode se efetivar de duas formas: avaliação de mérito (conteúdo) e de desempenho (forma). ${ }^{5}$

A primeira, normalmente realizada por pares (especialistas), pretende verificar aspectos como: qualidade dos artigos (originalidade, atualidade, identificação com a temática da revista e percentual de artigos originais), qualidade do corpo editorial e dos consultores (participação de membros da comunidade nacional e estrangeira), natureza do órgão publicador, abrangência, indexação, entre outros.

A segunda verifica aspectos como: normalização, duração, periodicidade, difusão, colaboração de autores e divisão de conteúdo. No ato da avaliação formal, a verificação do cumprimento dos critérios citados é realizada atribuindo-se pontos a cada item atendido, permitindo, assim, não apenas classificar os periódicos de acordo com seu grau de normalização, mas também possibilitando a caracterização de todo o conjunto no que diz respeito aos critérios mínimos exigidos de uma publicação para ser aceita pela comunidade científica.

Os critérios propostos nessa metodologia correspondem aos observados pelos indexadores IILACS - Literatura Latino-Americana e do Caribe em Ciências da Saúde e SciELO Brasil (Scientific Eletronic Library Online) para admissão e a permanência de títulos em suas bases de dados.

Para avaliação de forma das revistas, usamos o modelo proposto por Krzyzanowski \& Ferreira (1998) com algumas modificações para a área. De acordo com o formulário original, apresentado pelas autoras, os aspectos a serem observados são: normalização, duração, periodicidade, indexação, difusão (formas de distribuição), existência de coleção nas bibliotecas-base do Programa de Comutação Bibliográfica (COMUT), ${ }^{6}$ colabo- ração de autores e divisão de conteúdo.

A pontuação para cada variável e o total alcançado permitem uma classificação geral de desempenho de cada periódico analisado. Os periódicos avaliados, segundo as autoras, recebem, de acordo com o grau de suas pontuações, os seguintes desempenhos: MUITO BOM (81 pontosoumais), BOM (56a80pontos), MEDIANO (31 a 55 pontos) e FRACO (até 30 pontos).

Esse modelo apresenta uma versão para avaliação de periódicos das áreas de exatas e biológicas (1) e outro para os periódicos da área de humanas (2) que se diferem quanto ao item divisão de conteúdo.

O primeiro modelo citado (1) apresenta a divisão do conteúdo em: artigos originais, artigos de revisão, artigos de atualização, cartas, resenhas bibliográficas, comunicação de novas pesquisas e estudos de caso. $\mathrm{O}$ segundo modelo (2), para a área de humanas, apresenta a seguinte divisão: artigos ou ensaios, comunicação, cartas, documentos, registros e relatos, resenhas bibliográficas, entrevistas/depoimentos e outros.

Para atender melhor à avaliação de periódicos da Educação Física, promovemos algumas modificações no modelo proposto por Krzyzanowski \& Ferreira (1998). Decidimos pela supressão de alguns itens e pela modificação do sistema de pontuação, atribuindo um peso a cada variável presente no instrumento. As modificações são apresentadas a seguir.

A primeira modificação diz respeito à supressão do item "Existência em coleções razoavelmente completas em bibliotecas do sistema COMUT, uma vez que a falta de atualização das informações no Catálogo Coletivo Nacional de Publicações (CCN) do Instituto Brasileiro de Informação em Ciência e Tecnologia (IBICT) não gera informação confiável sobre o sistema COMUT.

A segunda modificação foi realizada no item "Divisão de conteúdo" em que optamos pela supressão dos itens "comunicação de novas pesquisas" e "artigos de atualização". De acordo com Souza (1992, p. 48), "...seções regulares de comunicação de novas pesquisas facilitam e agilizam a comunicação e disseminação de idéia". Entretanto, levando em consideração o estágio de de- 
senvolvimento da área, acreditamos que existem outros meios mais ágeis e econômicos para a divulgação e comunicação de novas pesquisas, por exemplo, as páginas de programas de pós-graduação, páginas de entidade científicas, correio eletrônico, etc. Além do que nos parece mais adequado uma nova pesquisa ser publicada como artigo original. Por esse motivo, decidimos pela supressão desse item.

A supressão do item "artigos de atualização" ocorreu em virtude da grande proximidade entre esse tipo de artigo e o de revisão. Um artigo de revisão pode apresentar o estado da arte de determinado objeto, expressando o que há de mais atual na literatura em relação a de. Assim, por entendermos que os dois tipos de artigos cumprem a mesma função, optamos pela supressão do artigo de atualização e pela permanência do artigo de revisão.

Decidimos desmembrar a variável duração em quatro itens: de 2 a 5 anos -2 pontos; de 6 a 10 anos - 3 pontos; de 11 a 15 anos - 4 pontos; mais de 15 anos - 5 pontos, e não mais atribuir um ponto a cada dois anos de publicação.

Essa modificação está fundamentada na literatura a que tivemos acesso sobre avaliação de periódicos, em que os avaliadores destacam que a variável duração pode influenciar a pontuação de uma revista. Como acreditamos que o fato de uma revista existir há mais tempo que outra não significa que ela possua melhor qualidade, embora o tempo de publicação possa influenciar esse aspecto, entendemos que não se pode atribuir peso excessivo a essa variável. ${ }^{7}$

No item "periodicidade", optamos por desmembrar o tempo de publicação, atribuindo um ponto a cada fascículo publicado pela revista por ano. Assim, uma revista anual receberá apenas um ponto, enquanto uma revista mensal receberá doze pontos.

Entendemos que o cumprimento da periodicidade deve ser valorizado, já que constitui uma das principais características das publicações periódicas, indicativa da agilidade da revista no processo de recebimento e publicação dos artigos.
Assim, o modelo (3) modificado e adaptado para a Educação Física propõe a observação dos seguintes critérios:

- normalização: os periódicos são avaliados seguindo-se as variáveis estabelecidas no formulário, recebendo pontuação de acordo com sua normalização. Como parâmetro para medir a normalização, consideram-se as normas da Associação Brasileira de Normas Técnicas (ABNT). No caso das referências, verifica-se qual a norma adotada e, a seguir, analisa-se se a revista cumpre a norma declarada.

- duração: considera-se a data de início e o tempo ininterrupto de existência do periódico para pontuação dessa variável, conforme especificado acima.

- periodicidade: a indicação de periodicidade é verificada no próprio periódico e confirmada no $\mathrm{CCN}$. Confere-se um ponto por fascículo publicado. Recebem um ponto a menos os fascículos atrasados e aqueles com números acumulados.

- indexação: recebem pontuação os fascículos que registram as fontes. Consideram-se até três fontes internacionais e atribuem-se a cada uma delas cinco pontos.

- difusão (formas de distribuição): são consideradas de "distribuição gratuita" e recebem um ponto nessa variável as publicações que não registram a forma de distribuição nos fascículos e/ou só fazem distribuição por doação e permuta. As publicações que indicam preço de assinatura recebem três pontos nessa variável.

- colaboração de autores: a publicação de trabalhos de autores estrangeiros, em colaboração ou não, é analisada e também pontuada. Recebem três pontos os fascículos que apresentam, pelo menos, $10 \%$ de artigos de autores estrangeiros.

- divisão de conteúdo: pretende identificar o tipo de artigo que é publicado pelo periódico. Considera os seguintes itens: artigo original, artigo de revisão, resenhas bibliográficas, cartas e relatos de experiência. Para a pontuação deste item, indicada no formulário, devese levar em consideração o número total de páginas do fascículo avaliado. 
Diante das modificações realizadas no instrumento, fezse necessária a alteração do sistema de pontuação, tendo em vista que as próprias autoras do modelo utilizado como base para o trabalho informam que "...se ocorrerem alterações no modelo, será necessário reorganizar a escala de pontuação para a obtenção do resultado final de desempenho" (Krzyzanowski \& Ferreira, 1998, p. 6).

Dessa forma, mantivemos a pontuação considerada no modelo para cada item avaliado, exceto nos itens duração e periodicidade, e atribuímos um peso a cada conjunto de variáveis para obtenção do desempenho geral, ficando assim distribuído: normalização - $25 \%$; duração- 5\%; periodicidade-12\%; indexação- $15 \%$; difusão - 3\%; e colaboração de autores e divisão de conteúdos- $40 \%$.

Assim, dentro de cada um desses conjuntos, há um número máximo de pontos que pode ser obtido pela revista. Para que se consiga o seu desempenho nesse item, deve-se relacionar, por meio de uma regra de três, o total de pontos obtidos pela revista dentro de determinado conjunto com o peso atribuído a ele.

O desempenho geral é obtido com a soma das pontuações alcançadas em cada um dos conjuntos, considerando, em nossa proposta, a seguinte classificação: NIVEL A-acima de 90\%;NÍVEL B-de71\%a90\%; NÍ-VEL C-de $51 \% a 70 \%$; NÍVEL Dde $31 \%$ a $50 \%$; NÍVEL E-menor ou igual a 30\%.

A pontuação pode ser visualizada melhor no seguinte quadro:

QUADRO 1-PONTUAÇÃO E PESO DOS CONJUNTOS

\begin{tabular}{c|c|c}
\hline CONJUNTO DE VARIÁVES & PONIUAÇÃO MAXIMA & PESO \\
\hline Normalizaçăo & 22 pontos & $25 \%$ \\
\hline Duraçăo & 05 pontos & $5 \%$ \\
\hline Periodicidade & 12 pontos & $12 \%$ \\
\hline Difusão & 03 pontos & $3 \%$ \\
\hline $\begin{array}{c}\text { Colaboraçăo de autores e } \\
\text { divisão de conteúdos }\end{array}$ & 17 pontos & $40 \%$ \\
\hline Indexação & 15 pontos & $15 \%$ \\
\hline & &
\end{tabular}

O peso atribuído a cada variável foi definido levando-se em consideração a importância de cada um dos itens dentro do conjunto da avaliação, buscando valorizar os aspectos que possam refletir com maior fidedignidade a qualidade das revistas e sendo mais condizente com a realidade das publicações periódicas da área.

\section{Considerações Finais}

OAo propormos um formulário para avaliação dos periódicos científicos da Educação Física, somos conduzidos pelo desejo de contribuir para a melhoria da qualidade de nossas publicações.

Pretendemos, com este artigo, alertar a comunidade científica da área sobre a importância do cumprimento das normas exigidas para publicação de artigos e periódicos. Mais do que mero "formalismo", trata-se de dotar a produção da área do rigor científico necessário para sua maior visibilidade. Esse rigor não se circunscreve ao "realizar pesquisa", mas também deve fazer parte do "comunicar a pesquisa", principalmente se atentarmos para o fato de que, sem publicação o desenvolvimento da Ciência fica comprometido.

A divulgação da produção científica pressupõe a adoção de padrões editoriais consistentes e a manutenção de uma periodicidade pontual e previsível. Não há dúvidas de que os aspectos formais, juntamente com a periodicidade e difusão são os mais fáceis de serem resolvidos. O mais difícil é fazer avançar o atual estágio de nossas publicações no que se refere ao seu envolvimento com a comunidade científica por meio de uma melhor relação entre editores, conselho editorial e autores.

Assim, faz-se necessário cuidar da qualidade da produção, que é o que confere autoridade científica ao periódico. Dessa forma, cada uma das revistas deve buscar aumentar a porcentagem de artigos originais em seus fascículos, definindo seções e estabelecendo em suas normas a concepção acerca da qualidade acadêmica dos artigos (artigos originais, artigos de revisão, estudo de caso, relato de experiência, pontos de vista, etc), visto que há uma correlação positiva entre autoridade cientí- 
fica do periódico e a qualidade da produção veiculada.

Alguns editores têm nos dado pistas da necessidade do envolvimento da comunicação científica na melhoria da qualidade de seus artigos. Apenas para citar um, entre os muitos exemplos em nossa área, podemos verificar os editoriais assinados por Abdallah Achour Júnior, na Revista Brasileira de Atividade Física \& Saúde.

Respectivamente, nos editoriais dos volumes 3 (3), 3 (4), 4 (1) e 5 (3) o editor tem buscado alertar a comunidade sobre a importância das publicações no contexto acadêmico e afirma que uma área de estudo somente se valoriza com a publicação da produção de um dado conhecimento que para ser elaborado exige organização e muito esforço para planejar, registrar, quantificar e interpretar os resultados de uma prática científica (Achour Júnior, 1998).

Dessa maneira, acreditamos que a realização da avaliação dos periódicos da Educação Física pode contribuir para que eles se tornem publicações mais eficazes no desempenho das suas funções na medida em que surge como possibilidade de desencadear entre os editores e comunidade cientifica da área em geral, um movimento para o aperfeiçoamento dessas publicações de forma a conferir a elas maior visibilidade.

Por ser a primeira experiência por nós realizada, sabemos que é passível de questionamento e reformulações. No entanto, as ações empreendidas devem ser entendidas como uma tentativa de acerto e sua divulgação

\section{Referências}

CASTRO,R.C.F.;FERREIRA,M.CG.;VIDILI,A.L. Periódicos latino-americanos: avaliação das características formais e sua relação com a qualidade científica. Ciência da Informação, Brasília, v. 25, n. 3, p. 357-67, set./dez. 1996.

CASTRO,R.C.F.;NEGRÃO,M.B.;ZAHER,C.R.Procedimentos editoriais na avaliação de artigos para publicação em periódicos de ciências da saúde da América Latina e Caribe.

Ciência da Informação, Brasília, v. 25, n. 3,1996. como tentativa de colaborar com os Assim, faz-se necessário editores que pas-cuidar da qualidade da sam pelos proble-produção, que é o que mas aqui tratados. confere autoridade

Mais do que méritos e defeitos, que certamente exis tem e que deverão ser aprimorados, a proposta apresentada busca ser es sencialmente pedagógica, buscando encontrar me-_concepção acerca da canismos que valo- qualidade acadêmica rizem as publica-dos artigos (artigos ções. $\quad$ originais, artigos de Todavia, isso ape- revisão, estudo de caso, nas se dará com o lato de experiencia, apoio e o en- visto que há uma volvimento da co- correlação positiva entre munidade cientí- autoridade científica do

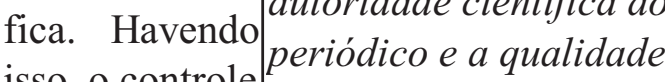
isso, o controle $\begin{aligned} & \text { periódico } \\ & \text { da produção veiculada. }\end{aligned}$ da qualidade das publicações se aperfeiçoará cada vez mais, seus resultados serão difundidos e ela tenderá a ser cada vez mais visível.

ACHOUR JUNIOR, A Editorial. Revista Brasileira de Atividade Física \& Saúde, Londrina, v. 3, n. 3, p. 1,1998. Editorial. Revista Brasileira de Atividade

Física \& Saúde, Londrina, v. 3, n. 4, p. 1,1998. . Editorial. Revista Brasileira de Atividade

Física \& Saúde, Londrina, v. 4, n. 1, p. 1,1999. . Editorial. Revista Brasileira de Atividade

Física \& Saúde, Londrina, v. 5, n. 3, p. 1,2000. 


\section{Modelo 1}

Modelo para avaliaçăo de periódicos científicos - Áreas de Exatas/Biológicas

Titulo

Instituiçãa

Volume (s) $\mathrm{N}^{\circ}$ Esıado

Agência Financiador

\begin{tabular}{|c|c|c|c|}
\hline 1.1 & Periódico no rodo & & \\
\hline \multirow[t]{2}{*}{ 1.1.1 } & Legenda bibliográfica & Indusâo (capa, sumário, paginats do texto) & 02 \\
\hline & & Existência & 01 \\
\hline \multirow[t]{2}{*}{$1 . \overline{1.2}$} & ISSN & Indusāo (capa, página de rosto efors sumário) & 02 \\
\hline & & Existência & 01 \\
\hline 1.1 .3 & Endereço & Completo & 01 \\
\hline 1.1 .4 & Periodicidade & Explicita & 01 \\
\hline \multirow[t]{2}{*}{1.1 .5} & lnsurụ̂es aos autors & Exiscência & 01 \\
\hline & & Complen (induindo exemplo de referências bibliogéficas) & 02 \\
\hline 1.2 & Fasciculo & & \\
\hline \multirow[t]{2}{*}{ 1.2.1 } & Sumário & Existência (lingua original) & 01 \\
\hline & & Existenncia (bilíngüe) & 02 \\
\hline \multirow[t]{3}{*}{1.2 .2} & Referèncias bibliográficas & & \\
\hline & Normalizadas (mais da metade dos artigns) & $0 \mathrm{l}$ & \\
\hline & Normatrzaçis expliáa (ISO, ABNT, CIDRM, ouros) & 02 & \\
\hline 1.3 & Artigos & & \\
\hline \multirow[t]{2}{*}{1.3 .1} & Filiaçāo autor & Indicaçäo incompleta & 01 \\
\hline & & Indicaçio completa & 03 \\
\hline \multirow[t]{2}{*}{$1,3.2$} & Resumos só no idioma do texto & & \\
\hline & & Indusio sistemática & 02 \\
\hline \multirow[t]{2}{*}{1.3 .3} & Resumas só em ouro idtioma que não o do texto & & \\
\hline & & Incluśo sistemánça & 02 \\
\hline 1.3 .4 & Resumos bilingües & Indusão sisternáuica & 04 \\
\hline \multirow[t]{2}{*}{1.3 .5} & Descritores & Indusäo en todoc as artigos & 02 \\
\hline & Indusäo em mais da metade dos artigos & 01 & \\
\hline \multirow[t]{2}{*}{ 1.3.6 } & Data de reatimento elou publicaçâo dos arigos & & \\
\hline & & Inclusāo sistemática & 01 \\
\hline 2 & DURAÇĀO & & \\
\hline \multirow[t]{2}{*}{2.1} & Tempo ininternupto de existência & & \\
\hline & & A cada dois anos & 01 \\
\hline 3 & PERIODICIDADE & & \\
\hline \multirow[t]{4}{*}{3.1} & Entervalo tegulat de aparição & & \\
\hline & & 1 vez ao ano & 00 \\
\hline & & 2 vezes ao ano & 0] \\
\hline & & 3 veres ao ano & 02 \\
\hline
\end{tabular}




\begin{tabular}{|c|c|c|}
\hline & & 4 veres an anto \\
\hline & & 6 vezes ao ano \\
\hline & & 12 vezes ao ano \\
\hline & Inegulares, atrasadas & 1 ponto a menos \\
\hline 4 & INDEXAÇÁO & \\
\hline \multirow[t]{2}{*}{4.1} & Indusio em biblioggrafias, abotracts, & \\
\hline & sumários correntes impressos ou em CD-ROM & Em cada servigo estangeiro elou internacional \\
\hline 5 & DFUSÄO & \\
\hline \multirow[t]{2}{*}{5.1} & Formas de distribuição & Compra efou permuta \\
\hline & & Distribuiç̧o gratuita \\
\hline \multirow[t]{2}{*}{5.2} & Existência etn coleģōes razodavelmente complecas & \\
\hline & em bibliotecas do sistema & A cada biblioteca que possuir ao menos $75 \%$ da coleçio \\
\hline 6 & COLABORAÇĀO EDVISĀO DE CONIEÚDO & \\
\hline 6.1 & Auttoria & Prublicação de no mírimo $10 \%$ de artigros de autores estrangeiros el ou em colaboração \\
\hline 6.2 & Ditsiäo de contreido & \\
\hline \multirow[t]{2}{*}{6.2 .1} & Artigos originais & Inclusion regular de $75 \%$ \\
\hline & & Indusĩo regular de $50 \%$ \\
\hline 6.2 .2 & Artigur de tevisäo & Enclusăo regular \\
\hline 6.2 .3 & Comunicaça de roxas pesquilas & Inclusão tegular \\
\hline 6.2 .4 & Cartas & Inclusĩo regular \\
\hline 6.2 .5 & Rexerthas biblioggáficas & Inclusão regular \\
\hline 6.2 .6 & Arrigos de atualização & lnclusáo regular \\
\hline 6.2 .7 & Estudos de caso & Inclusiono regular \\
\hline
\end{tabular}

Fonte: Krzyzanowski \& Ferreira, 1998

\section{Modelo 2}

Modelo para avaliaçăo de periódicos científicos - Áreas de Humanas

\begin{tabular}{|c|c|c|}
\hline 6.2 & Ditrsäo de conterido & \\
\hline \multirow[t]{2}{*}{6.2 .1} & Artigos /Ensios & Irxdusio regutar de $75 \%$ \\
\hline & & Indusso regubar de $50 \%$ \\
\hline 6.2 .2 & Comunicaraio & Indusío regular \\
\hline 6.2 .3 & Cartas, documentos, registros, nelaros & Indusiäo regutar \\
\hline 6.2 .4 & Resenhas bibliograficicas & Indusian regular \\
\hline 6.2 .5 & Envevistas, depoimentes, etc. & Indusäo negular \\
\hline 6.26 & Outros & Indusio regutar \\
\hline
\end{tabular}

Fonte: Krzyzanowski \& Ferreira, 1998 


\section{Modelo 3}

Modelo para avaliação de periódicos científicos - Educação Física

Titulo

Insrituiçâa_

Volume $(s) \_N^{\circ}$ ____ Esrado_______ Agência Financiadora

\begin{tabular}{|c|c|c|}
\hline 1 & NORMALIZAÇAO & \\
\hline 1.1 & Periódico no todo & \\
\hline \multirow{2}{*}{1.1 .1} & Legenda bibliográfica & Inclusão (capa, sumário, páginas do texro) \\
\hline & & Existência \\
\hline \multirow[t]{2}{*}{1.1 .2} & ISSN & Inclusão (capa, página de rosto elou sumário) \\
\hline & & Exisrência \\
\hline 1.1 .3 & Endereço & Completo \\
\hline 1.1 .4 & Periodicidade & Explicita \\
\hline \multirow[t]{2}{*}{1.1 .5} & Instruçóes aos autores & Exisrềncia \\
\hline & & Completa (incluindo exemplo de referências) \\
\hline 1.2 & Fascículo & \\
\hline \multirow[t]{2}{*}{$1.2,1$} & Sumário & Existência (língua original) \\
\hline & & Existência (bilingüe) \\
\hline \multirow[t]{2}{*}{1.2 .2} & Referências & Normalizadas (mais da metade dos artigos) \\
\hline & & Notmalização explicita (ISO, ABNT, CIDRM, outros) \\
\hline 1.3 & Arrigos & \\
\hline \multirow[t]{2}{*}{1.3 .1} & Filiação auror & Indicaçăo incompleta \\
\hline & & Indicaçăo completa \\
\hline 1.3 .2 & Resumos só no idioma do texto & Inclusão sistemática \\
\hline \multirow[t]{2}{*}{1.3 .3} & Restumos só em outro idioma & \\
\hline & que năo o do texto & Inclusão sistemárica \\
\hline 1.3 .4 & Resumos bilíngües & Inclusão sistemática \\
\hline \multirow[t]{2}{*}{1.3 .5} & Descritores & Inclusảo em todos os artigos \\
\hline & & Inclusão em mais da metade dos arrigos \\
\hline \multirow[t]{2}{*}{1.3 .6} & Data de tecebimento elou & \\
\hline & publicação dos arrigos & Inclusão sistemática \\
\hline 2 & DURAÇÄO & \\
\hline \multirow[t]{4}{*}{2.1} & Tempo ininterrupto de existência & 2 a 5 anos \\
\hline & & 6 a 10 anos \\
\hline & & 11 a 15 anos \\
\hline & & Mais de 15 anos \\
\hline
\end{tabular}




\begin{tabular}{|c|c|c|}
\hline 3 & PERODLODADE & \\
\hline \multirow[t]{13}{*}{3.1} & Intervalo regular de apariçäo & I vez ao ano \\
\hline & & 2 vezes ao ano \\
\hline & & 3 vezes $x$ ano \\
\hline & & 4 vezes an ano \\
\hline & & 5 vezes an ano \\
\hline & & 6 vezes ao ano \\
\hline & & 7 vezes ao ano \\
\hline & & 8 veres to aro \\
\hline & & 9 vezes ao ano \\
\hline & & 10 vezes an ano \\
\hline & & 11 vezes ao ano \\
\hline & & 12 vezes ao ano \\
\hline & Inegulares, arrasadas & 1 ponto a menos \\
\hline 4 & DIFUSÄO & \\
\hline \multirow[t]{2}{*}{4.1} & Formas de disrribuiçán & Compra elou permuta \\
\hline & & Distribuiçâio gratuita \\
\hline 5 & COLABORACĀOEDMLÄO DEOONIEÚDO & \\
\hline 5.1 & Auroria & 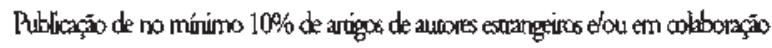 \\
\hline 5.2 & Ditrisido de contetido & \\
\hline \multirow[t]{2}{*}{5.2 .1} & Artiges originais & Inclusio regular de $75 \%$ (do wonl de páginas da tevisa) \\
\hline & & lncluño regular de $50 \%$ (do total de páginas da revista) \\
\hline 5.2 .2 & Arrigos de revišö & Indusão negular \\
\hline 5.2 .3 & Cartas & Indusío regular \\
\hline $5,2,4$ & Resenhas bibliograficas & Inclusāo regular \\
\hline 5.2 .5 & Enuxlos de caso & Inclusio regular \\
\hline 6 & INDEXACÁO & \\
\hline \multirow[t]{2}{*}{6.1} & Inclusäio em bibliografias, abstracts, sumátios & \\
\hline & contentes imprexos ou em CD-ROM & En cada serviço interrecional \\
\hline
\end{tabular}

Fonte: modificado a partir de Krzyzanowski \& Ferreira, 1998 
FÁVERO, M. L. de A. A produção científica sobre educação superior anotações para um debate. In: MOROSINI, M.; GUISSARDI, V. A educação superior em periódicos nacionais. Vitória: FCAA/UFES, 1998.

KRZYZNOWSKI,RE,FERREIRA,M.C.G.Avaliaçãode periódicos científicos e técnicos brasileiros. Ciência da Informação, Brasília, v. 27, n. 2, p. 165-175, maio/ago. 1998.

LILACS - Literatura Latino-Americana e do Caribe em Ciências da Saúde. Critérios de Seleção de periódicos para a base de dados LILACS. 2000. Disponível em: $<$ http://www.bireme.br/abd/P/crit Selecao.html $>$ Acesso em:19agp.2001.

MEADOWS, A. J. A comunicação científica. Tradução de Antônio Agenor Briquet de Lemos. Brasília, DF: Briquet de Lemos/Livros, 1999.

MIRANDA, D. B. O periódico científico como veículo de comunicação: uma revisão de literatura. Ciência da Informação, Brasília, v. 25, n. 3,1996.

MUEILER S. P. M. O círculo vicioso que prende os periódicos nacionais. DataGramaZero, Brasília, n. 0, dez. 1999.

OHIRA,M.LB.;SOMBRIO,M.L.L.N.; PRADO,N.P. Periódicos brasileiros especializados em biblioteconomia e ciência da informação. Encontros Bibli: Revista de Biblioteconomia e Ciência da Informação, Florianópolis, n. 10, out. 2000. Disponível em: $\leq$ http:// www.ced.ufsc.br/bibliote/encontro $>$.

\section{SABBATINI, M. As publicações eletrônicas dentro da} comunicação científica. 1999. Disponível em: <http:// bocc.ubi.pt/pag/sabbatini-marcelo-publicacoeseletronicas.html $>$ Acesso em: 15 jun.2002.

SCIENTIFIC Eletronic Library Online. Biblioteca Científica Eletrônica. Critérios SciELO Brasil: critérios, política e procedimentos para a admissão e a permanência de periódicos científicos na coleção SciELO Brasil.2000. Disponível em: < http://www.scielo.br/> Acesso em: 19 ago.2001.

SOUZA, D. H. F. de. Publicações periódicas: processos técnicos, circulação e disseminação seletiva da informação. Belém: Universidade Federal do Pará, 1992.
STUMPF, I. R. C. Passado e futuro das revistas científicas. Ciência da Informação, Brasília, v. 25, n. 3, p. 383386,1996 .

. Revistas universitárias brasileiras: barreiras na sua produção. Transinformação, v. 9, n. 1, jan./abr. 1997.

. Reflexões sobre as Revistas Brasileiras. In texto, v. 1, n. 3,2000. Disponível em: < file://

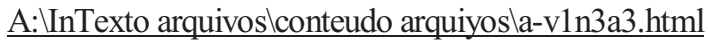
$>$ Acesso em: ago. 2001.

TARGINO, Manadas Graças. Comunicação científica: uma revisão de seus elementos básicos. Informação \&

Sociedade, v. 10, n. 2, p. 37-85.2000.

TARGINO,M. dasG.;GARCIA,J.C.R. Ciência brasileira na base de dados do Institute for Scientific Information. Ciência da Informação, Brasília, v. 29, n. 1, p. 103-126, jan./abr.2000.

YAMAMOTO, O. H. et al. Periódicos científicos em psicologia: uma proposta de avaliação. Infocapes, v. 7, n. 3, p. 7-13, juL/set 1999.

\section{Notas}

* Doutor em Educação pela Universidade Metodista de Piracicaba

Professor do Departamento de Desportos da Universidade Federal do Espírito Santo

Coordenador do PROTEORIA- Instituto de Pesquisa em Educação e Educação Física

** Graduada em Comunicação Social e Educação Física pela Universidade Federal do Espírito Santo

Membro do PROTEORIA- Instituto de Pesquisa em Educação e Educação Física

${ }^{1}$ No texto, as expressões divulgação, disseminação e difusão são usadas como equivalentes, já que não é nosso objetivo nos aprofundar na discussão que busca depurar o quadro conceituai que engloba os termos que se referem à idéia de "fazer circular" a ciência. Sobre essa discussão ver: ZAMBONI, L. M. S. Cientistas, jornalistas e a divulgação científica: subjetividade e heterogeneidade no discurso da divulgação científica. Campinas, SP. Autores Associados, 2001. 
${ }^{2}$ A palavra revista é empregada neste artigo em referência a uma publicação periódica de uma coletânea de artigos científicos escritos por diferentes autores. Ou seja, como sinônimo de periódico. Sobre o uso das palavras revistas, periódicos, magazine ejournal, consultar: MEADOWS, 1999.

${ }^{3}$ Como exemplo verificar relatórios de avaliação dos periódicos da Educação e Psicologia publicados, respectivamente em: ABT, ANPEd, INEP, CAPES. Relatório da avaliação dos periódicos brasileiros de educação realizada em 2001. Disponível em < www.anped.org.br/aval2001.htmp. Acesso em: out.2001.

e YAMAMOTO,etá,1999.

${ }^{4} \mathrm{O}$ formulário proposto foi testado nos seguintes periódicos da Educação Física: Revista Brasileira de Ciências do Esporte, Revista Motus Corporis, Revista Paulista de Educação Física, Revista Brasileira de Ciência e Movimento, Revista Movimento, Revista Motrivivência, Revista Mineira de Educação Física, Revista da Educação Física/UEM, Revista Motriz, Revista Licere e Revista Kinesis. Os relatórios dos periódicos analisados podem ser encontrados na página do PROTEORIA, no seguinte endereço: www.proteoria.net (ícone Avaliação de periódicos científicos).

${ }^{5}$ Metodologia proposta por Krzyzanowski \& Ferreira (1998) para avaliação de periódicos científicos e técnicos brasileiros. É recomendável, no estágio de desenvolvimento dos periódicos científicos da Educação Física, que a comunidade científica conheça os critérios Lilacs e Scielo Brasil.

${ }^{6}$ COMUT - O Programa de Comutação Bibliográfica foi criado pela Portaria n. 456, de 05-08-1980, do Ministério da Educação e Cultura do Brasil, com a finalidade de solucionar os problemas de acesso e de disponibilidade dos documentos. Está baseado em uma rede de Bibliotecas Universitárias e especializadas, visando a melhorar as condições de pesquisa bibliográfica dos estudantes, professores e pesquisadores. Para operacionalizar o Serviço de Comutação, foi criado um convênio entre 83 bibliotecas-base que se propuseram a manter atualizados os seus acervos no Catálogo Coletivo Simplificado (Souza, 1992).

${ }^{7}$ Sobre o assunto ver os trabalhos: CASTRO, FERREIRA \& VILILI, 1996, e KRZYZANOWSKI \& FERREIRA 1998.
Endereço para correspondência:

Amarílio Ferreira Neto

CaixaPostal Ol-9030

ACF- Campus Universitário

Vitória-ES

CEP29060-973

E-mail: proteoria@proteorianet

Tel: (27) 3335-7680

Recebido: 24/06/02

Acato: $10 / 07 / 02$ 
